The University of Maine

\title{
DigitalCommons@UMaine
}

Maine-Syracuse Longitudinal Papers

Maine-Syracuse Longitudinal Study

1994

\section{Effects of Antihypertensive Medications on Quality of Life in Elderly Hypertensive Women}

Sydney H. Croog

Merrill F. Elias

University of Maine - Main, mfelias@maine.edu

Theodore Colton

Robert M. Baume

Sandra R. Leiblum

See next page for additional authors

Follow this and additional works at: https://digitalcommons.library.umaine.edu/ longitudinal_papers

Part of the Cardiovascular System Commons, and the Chemicals and Drugs Commons

\section{Repository Citation}

Croog, S. H., Elias, M. F., Colton, T., Baume, R. M., Leiblum, S. R., Jenkins, C. D., Perry, H. M., \& Hall, W. D. (1994). Effects of antihypertensive medications on quality of life in elderly hypertensive women. The American Journal of Hypertension, 7, 329-339.

This Article is brought to you for free and open access by DigitalCommons@UMaine. It has been accepted for inclusion in Maine-Syracuse Longitudinal Papers by an authorized administrator of DigitalCommons@UMaine. For more information, please contact um.library.technical.services@maine.edu. 
Authors

Sydney H. Croog, Merrill F. Elias, Theodore Colton, Robert M. Baume, Sandra R. Leiblum, C David Jones, H Mitchell Perry, and W Dallas Hall 

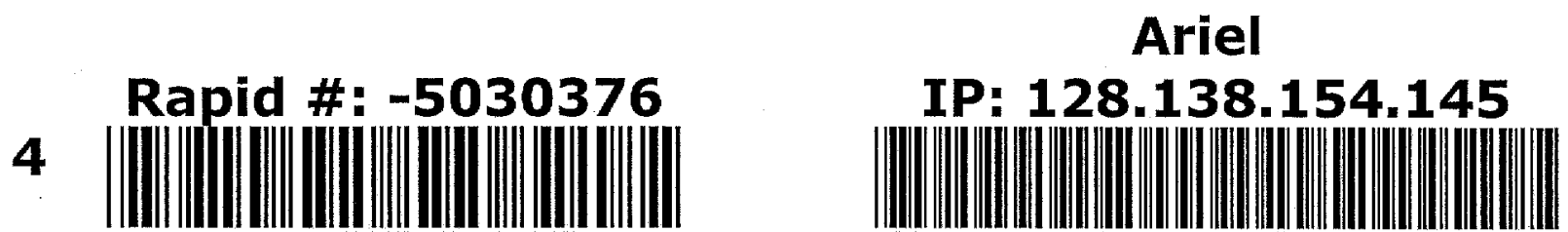

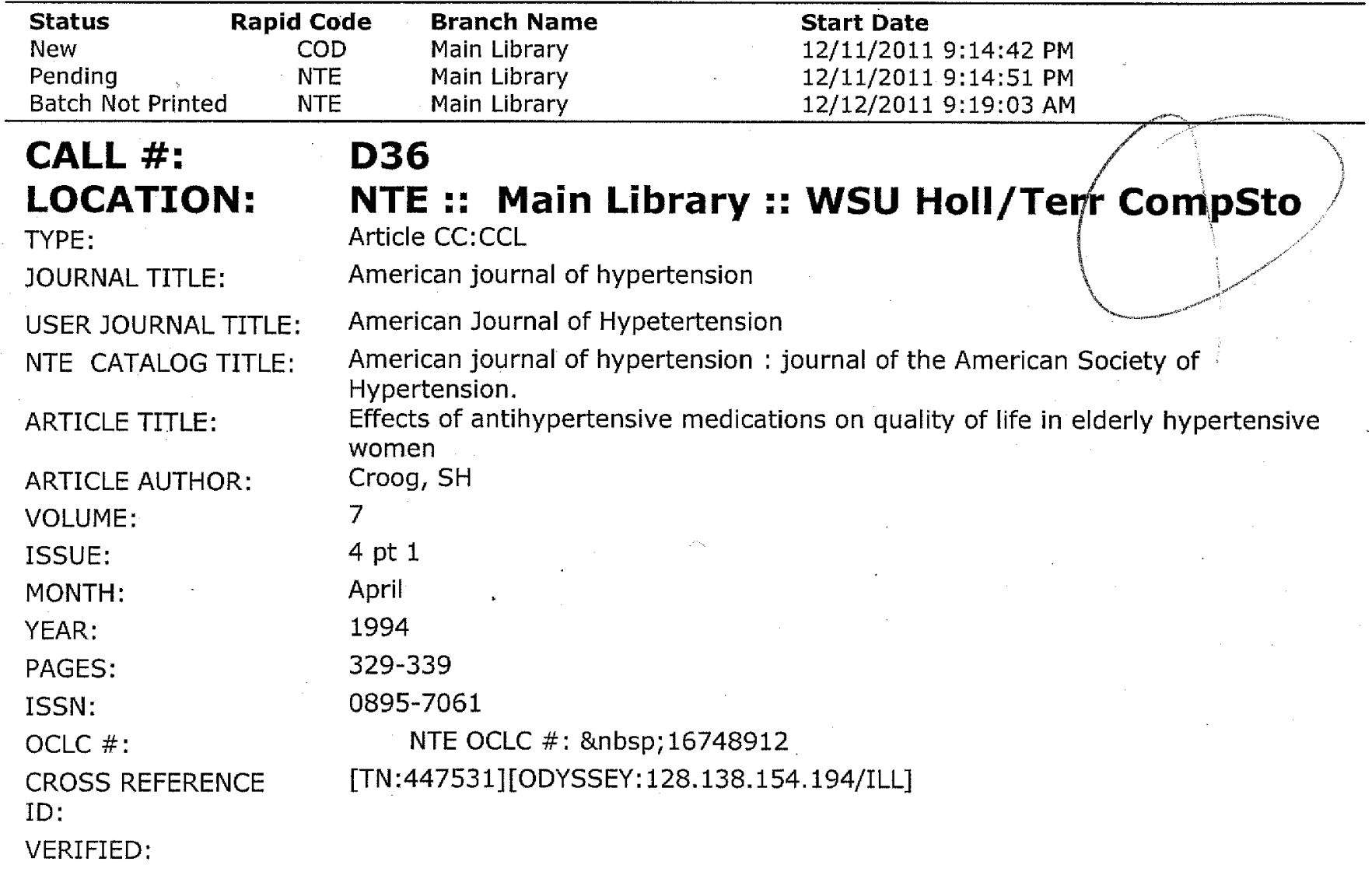

\section{BORROWER: COD :: Main Library} PATRON:

PATRON ID:

PATRON ADDRESS:

PATRON PHONE:

PATRON FAX:

PATRON E-MAIL:

PATRON DEPT:

PATRON STATUS:

PATRON NOTES: 


\title{
Effects of Antihypertensive Medications on Quality of Life in Elderly Hypertensive Women
}

\author{
Sydney H. Croog, Merrill F. Elias, Theodore Colton, Robert M. Baume, Sandra R. Leiblum, \\ C. David Jenkins, H. Mitchell Perry, and W. Dallas Hall
}

The impact of antihypertensive medications on the quality of life of elderly hypertensive women has rarely been systematically evaluated in large clinical trials using drugs from the new generations of pharmaceutic preparations. We carried out a multicenter, randomized double-blind clinical trial with 309 hypertensive women aged 60 to 80 years to assess effects of atenolol, enalapril, and isradipine on measures of quality of life over a 22-week period. The patients had mild to moderate hypertension. Hydrochlorothiazide was added to treatment if monotherapy was inadequate in lowering blood pressure. At the conclusion of the trial the three drug groups did not differ in degree of reduction of diastolic blood pressure or in supplementation with hydrochlorothiazide. Over the 22-week trial, linear trend analysis showed no differences between the treatment groups in change from baseline on quality of life measures of well-being, physical status, emotional status, cognitive func- tioning, and social role participation. Regarding each of 33 physical side effects over the 22 weeks, we found no general difference between atenolol, enalapril, and isradipine groups on measures of change in distress over symptoms except for enalapril patients who worsened in distress over cough $(P=.001)$ and atenolol patients who worsened in distress over dry mouth $(P=.014)$. Centering on three medications that are latively new additions to the armamentarium for blood pressure control, the findings underline the increasing opportunities for the physician to select drugs that can control blood pressure while maintaining the quality of life of elderly hypertensive women. Am J Hypertens 1994;7:329-339

KEY WORDS: Hypertension, elderly women, quality of life, atenolol, enalapril, isradipine, hypertension drug therapy, aging.
Received June 22, 1993. Accepted November 30, 1993

From the Department of Behavioral Sciences and Community Health, University of Connecticut Health Center, Farmington, Connecticut (SHC, RMB); Department of Psychology, University of Maine, Orono, Maine (MFE); Department of Epidemiology and Biostatistics, Boston University School of Public Health, Boston Massachussetts (TC); Department of Psychiatry, Robert Wood Johnson Medical School, Piscataway, New Jersey (SRL); The Department of Preventive Medicine and Community Health, University of Texas Medical Branch, Galveston, Texas (CDJ); Department of Medicine, Washington University School of Medicine, St. Louis, Missouri (HMP); Department of Medicine, Emory University School of Medicine, Atlanta, Georgia (WDH).

Supported by a grant from Glaxo, Inc., Research Triangle Park, North Carolina.

Address correspondence and reprint requests to Dr. Sydney $\mathrm{H}$. Croog, University of Connecticut Health Center, Farmington, CT 06030.

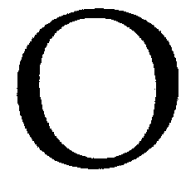
ver recent years increasing attention has focused on issues of treatment of the older female hypertensive. Among women 65 to 74 years old, an estimated $50 \%$ are hypertensive, with blood pressures $\geq 160$ $\mathrm{mm} \mathrm{Hg}$ systolic and $95 \mathrm{~mm} \mathrm{Hg}$ diastolic. ${ }^{1,2}$ Treatment of high blood pressure in the elderly predominantly involves the female hypertensive, as women comprise approximately two-thirds of the hypertensive persons 65 years old and over. Elderly hypertensive patients are likely to differ from younger patients, in such measures as higher total peripheral resistance, lower blood volume, lower cardiac out- 
put, and lower plasma renin activity.,4 Some negative effects of antihypertensive medications on quality of life may lead to withdrawal from treatment or poor compliance by the patient. ${ }^{4}$ Drug trials with predominantly middle-aged, hypertensive patients have shown that while medications may have similar efficacy, their side effects and impact on quality of life may differ ${ }^{5,6}$ However, findings from such studies cannot be generalized readily to elderly hypertensive women.

New generations of antihypertensive drugs are being developed, including refinements of calcium channel blockers, $\beta$-blockers, and angiotensin converting enzyme (ACE) inhibitors. ${ }^{7-10}$ Recently, increasing numbers of clinical trials have examined various drugs within these classes of antihypertensive medications in terms of their effects on quality of life, with most centering on either male patients or on patient populations not differentiated by sex in the analysis. ${ }^{11-18}$ Relatively little documentation is available on the effects of such antihypertensive medications on quality of life in the elderly, as the issue has rarely been examined systematically in large, randomized clinical trials. ${ }^{19,20}$ Assessment of effects of the medications on elderly female hypertensives requires focus both on the pharmacologic treatment and on quality of life in the context of aging. ${ }^{21-24}$

This report presents findings on measures of quality of life from a randomized, multicenter, doubleblind clinical trial with 309 elderly female hypertensive patients. We assessed effects of three differing classes of antihypertensive medications, drawn from recent generations of pharmacologic agents: atenolol (a cardioselective $\beta$-blocker), enalapril (an angiotensin converting enzyme [ACE] inhibitor), and isradipine (a dihydropyridine calcium channel blocker). We examined change scores in quality of life measures after both 6 weeks and 22 weeks of treatment as well as the possible relationship of age and dosage level to the change scores. Looking beyond differences between treatment groups, we analyzed trend data for the total study group to document changes in quality of life scores during treatment with these medications. A report comparing efficacy and safety of the three drugs appears in a separate publication. ${ }^{25}$

\section{PATIENTS AND METHODS}

Study Subjects and Eligibility Criteria The study subjects were postmenopausal white women aged 60 to 80 years with mild to moderate essential hypertension (ie, 95-114 mm Hg sitting diastolic blood pressure). They were recruited at 22 clinical centers throughout the United States. Eligibility criteria at initial screening included demonstrated potential for completion of the quality of life and cognitive scales used in this study: a score of 7 or lower on the Jaeger scale for the Rosenbaum Vision test, ${ }^{26} 42$ or above on the WRAT Reading Test, ${ }^{27}$ and 12 or fewer incorrect answers on the Mini Mental State Exam. ${ }^{28}$

Patients with any of the following were excluded: severe cardiac disease, secondary hypertension, uncontrolled diabetes, recent cerebrovascular accident, bronchospasm requiring chronic treatment, significant hepatic or renal disease, intolerance to the study drugs, treatment with psychotrophic drugs or any other medication that could affect blood pressure or emotional status, and presence of any other condition that could limit the patient's capacity for completion of all phases of this study. Current treatment with estrogen, progesterone, or androgens was not a reason for exclusion. If drugs for chronic conditions were essential for the patient's well-being, they were continued at the same dose throughout the study.

An $80 \%$ compliance rate was required for continuation in the study, defined as return of no greater than $20 \%$ of capsules at each visit. The research protocol was approved by appropriate institutional review boards, and informed consent was obtained from all study subjects.

Study Design After a placebo period of 4 to 8 weeks, subjects were randomized to one of the three treatment groups. The first active treatment period extended for 6 weeks (titration stage), followed by 16 weeks on maintenance therapy. Quality of life assessments were carried out at baseline at the end of the placebo period, at 6 weeks, and at 22 weeks.

Medication was titrated upward every 2 weeks until blood pressure was controlled. Control was defined as the reduction of sitting diastolic blood pressure to $<90 \mathrm{~mm} \mathrm{Hg}$ and at least $10 \mathrm{~mm} \mathrm{Hg}$ below the baseline value. The three-step titration schedule was: atenolol $50 \mathrm{mg}, 100 \mathrm{mg}, 100 \mathrm{mg}$; enalapril $5 \mathrm{mg}$, 10 $\mathrm{mg}$, $20 \mathrm{mg}$; isradipine $1.25 \mathrm{mg}, 2.5 \mathrm{mg}$, and $5.0 \mathrm{mg}$. Atenolol and enalapril were prescribed once daily and isradipine was prescribed twice daily. To maintain blinding, patients receiving atenolol and enalapril took a placebo in the evening. If blood pressure was not controlled at the end of titration, open label hydrochlorothiazide (HCTZ), $25 \mathrm{mg}$ daily, was added.

Patients were withdrawn from the study if their blood pressure remained uncontrolled after the administration of HCTZ, or if an intolerable adverse effect developed. Patients who withdrew during the active treatment period were requested to complete an exit interview.

Data Collection and Management Quality of life assessments were carried out by personnel who had received standardized training for the interviewing and administration of psychological testing. Interviewers were not directly involved in patient care. Patients, interviewers, and investigators were blinded to the primary treatment drug assignments.

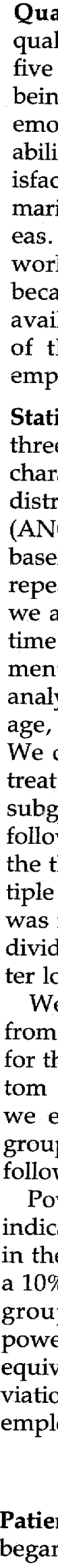


Quality of Life Assessment Assessment of the quality of life construct was guided by specification of five conceptual dimensions: ${ }^{29,30}$ (1) the sense of wellbeing and satisfaction with life, (2) physical state, (3) emotional state, (4) intellective functioning, and (5) ability to perform social roles and the degree of satisfaction derived from those roles. Appendix A summarizes measures within each of the conceptual areas. Data on measures of sexual performance and work satisfaction are not included in this report because of insufficient numbers of patients with available, functional sexual partners and because of the small number of respondents who were employed.

Statistical Analyses For baseline comparisons of the three treatment groups on demographic and clinical characteristics, quality of life scales, and symptom distress scores, we used one-way analysis of variance (ANOVA). Our analyses of quality of life scales at baseline and at weeks 6 and 22 of follow-up used repeated measures ANOVA. Within these ANOVAS, we also segregated and tested for linear trends over time as well as for interaction of linear trends by treatment groups. We also conducted repeated measures analyses of covariance where we used as covariates age, titration level, and/or the addition of diuretics. ${ }^{31}$ We conducted these analyses both for the intent-totreat group of all randomized patients and for that subgroup of patients who completed the entire study follow-up protocol. For pairwise comparisons among the three treatment groups, we used the Tukey multiple range test. ${ }^{32}$ In several instances, where there was indication of skewness in the distribution of individual scale results, we conducted our analyses after logarithmic transformation of the raw data.

We also conducted separate analyses of change from baseline to week 6 and from baseline to week 22 for the quality of life scales and the individual symptom distress scores. For within-group comparisons we employed paired samples $t$ tests; for betweengroup (ie, drugs) comparisons we used ANCOVA followed by the Tukey multiple range test. ${ }^{32}$

Power calculations with the quality of life measures indicated that the sizes of the three treatment groups in the intent-to-treat sample were sufficient to detect a $10 \%$ difference in a comparison of any of two drug groups, or a medium effect size 0.25 with $95 \%$ power ${ }^{33}$ and a two-tailed test at the $5 \%$ level. This is equivalent to a difference of about 0.45 standard deviations in change scores across the full set of scales employed.

\section{RESULTS}

Patient Population We recruited 517 patients who began the placebo period. The 202 patients who did not complete the placebo period failed to do so mainly because of blood pressure levels that did not meet study criteria, presence of concomitant illnesses, and adverse events. Upon completion of the placebo period, 315 patients were randomized. Of these, six completed only baseline interviews ( 1 atenolol, 2 enalapril, and 3 isradipine) and have been excluded from further analyses. The remaining 309, which we consider the "intent-to-treat" group, consisted of 103 randomized to atenolol, 101 to enalapril, and 105 to isradipine.

By week 6,7 of the 309 intent-to-treat patients had withdrawn, and by week 22 an additional 62 patients had done so. Of the total 69 patients withdrawn, the major reasons were adverse reactions $(n=42)$ and unacceptably elevated blood pressure $(n=19)$. The number of withdrawals by treatment group were: 29 on atenolol $(28.2 \%), 17$ on enalapril $(16.8 \%)$, and 23 on isradipine $(20.0 \%)$. The three treatment groups did not differ significantly in rate of withdrawal. Data for the intent-to-treat analysis are based on interviews with the completer population, exit interviews with withdrawing patients, and the most recent interviews with withdrawers in the absence of formal exit interviews. Patients who withdrew did not differ in demographic characteristics or baseline quality of life measures from the remaining 240 patients who completed the entire study.

Table 1 shows the distribution of highest titrated drug level within each drug treatment group among the 240 patients who completed the study. For the atenolol group, steps 2 and 3 were identical in prescription at $100 \mathrm{mg} /$ day, in accordance with a procedure to maintain blinding. Thus, in analyses relating to titration level for the atenolol group, steps 2 and 3 were combined. The percentage of patients who took the diuretic in addition to the main treatment drug did not differ between treatment groups.

Table 2 shows demographic and clinical characteristics of the three randomized treatment groups. Table 3 shows baseline means on quality of life measures in the first three columns. There were no significant differences between treatment groups at baseline in demographic or clinical variables or quality of life measures.

Effects of Drugs on Blood Pressure Reduction Among patients completing the study, including those on monotherapy or the primary treatment plus hydrochlorothiazide, reductions in sitting diastolic blood pressure from baseline to week 22 were comparable (mean $\pm \mathrm{SE}$ ) $15.6 \pm 0.7 \mathrm{~mm} \mathrm{Hg}, 15.1 \pm 0.9$ $\mathrm{mm} \mathrm{Hg}$, and $16.2 \pm 0.7 \mathrm{~mm} \mathrm{Hg}$ for the atenolol, enalapril, and isradipine groups, respectively. These 
TABLE 1. DRUG TITRATION. PATIENTS WHO COMPLETED THE TRIAL, CLASSIFIED BY HIGHEST DOSAGE LEVEL OF TREATMENT MEDICATION USED DURING THE STUDY

\begin{tabular}{|c|c|c|c|c|c|c|c|c|c|}
\hline \multirow[b]{2}{*}{$\begin{array}{l}\text { Titration } \\
\text { Step }\end{array}$} & \multicolumn{3}{|c|}{ Atenolol } & \multicolumn{3}{|c|}{ Enalapril } & \multicolumn{3}{|c|}{ Isradipine } \\
\hline & $\begin{array}{c}\text { Dosage } \\
\text { Level }\end{array}$ & $\mathbf{n}$ & Percent & $\begin{array}{c}\text { Dosage } \\
\text { Level }\end{array}$ & $\mathbf{n}$ & Percent & $\begin{array}{c}\text { Dosage } \\
\text { Level }\end{array}$ & $\mathbf{n}$ & Percent \\
\hline 1 & $50 \mathrm{mg} \mathrm{qd}$ & 34 & 46.0 & $5 \mathrm{mg} \mathrm{qd}$ & 30 & 35.7 & $1.25 \mathrm{mg}$ bid & 21 & 25.6 \\
\hline 2 & $100 \mathrm{mg} \mathrm{qd}$ & & & $10 \mathrm{mg} \mathrm{qd}$ & 16 & 19.1 & $2.5 \mathrm{mg}$ bid & 29 & 35.4 \\
\hline 3 & $100 \mathrm{mg} \mathrm{qd}$ & 28 & 37.8 & $20 \mathrm{mg} \mathrm{qd}$ & 20 & 23.8 & $5.0 \mathrm{mg}$ bid & 23 & 28.0 \\
\hline 4 & $\begin{array}{l}100 \mathrm{mg} \text { qd } \\
\text { plus HCTZ }\end{array}$ & 12 & 16.2 & $\begin{array}{l}20 \mathrm{mg} \text { qd } \\
\text { plus HCTZ }\end{array}$ & 18 & 21.4 & $\begin{array}{l}5.0 \mathrm{mg} \text { bid } \\
\text { plus HCTZ }\end{array}$ & 9 & 11.0 \\
\hline Total & & 74 & 100.0 & & 84 & 100.0 & & 82 & 100.0 \\
\hline
\end{tabular}

HCTZ, hydrochlorothiazide; qd, every day; bid, twice daily.

changes were all statistically significant $(P<.001)$. The systolic blood pressure reductions from baseline to week 22 were $15.2 \pm 1.9 \mathrm{~mm} \mathrm{Hg}, 21.3 \pm 2.0 \mathrm{~mm}$ $\mathrm{Hg}$, and $18.0 \pm 1.6 \mathrm{~mm} \mathrm{Hg}$ in the atenolol, enalapril, and isradipine groups, respectively. There were no significant differences between treatment groups in diastolic and systolic blood pressure reduction with the exception of a decrease in the enalapril group in systolic blood pressure that was greater than that in the atenolol group $(P=.048)$.

Patient Withdrawals and Adverse Events The three treatment groups did not differ in the proportion of withdrawals because of adverse events over the 22week trial: atenolol $(\mathrm{n}=17$ or $16.3 \%)$, enalapril $(\mathrm{n}=$ 13 or $12.6 \%$ ), and isradipine ( $\mathrm{n}=12$ or $11.1 \%$ ).

Primary adverse events associated with withdrawal among the drug groups were: atenolol: bradycardia $(\mathrm{n}=5)$, dyspnea $(\mathrm{n}=3)$, and headaches $(\mathrm{n}=2)$; enalapril: cough $(n=3)$ and orthostatic hypotension
( $n=2)$; isradipine: dizziness ( $n=3$ ), edema of extremities ( $n=2)$, headache $(n=2)$, and palpitations $(n=2)$. Miscellaneous individual adverse reactions also occurred.

Quality of Life: Changes in Scale Scores Between Treatment Groups: Baseline to Week 6 and Week 22 In the intent-to-treat repeated measures analysis of comparisons between treatment groups, we found no differences between groups in change in scores on any of the quality of life scale measures from baseline to weeks 6 and 22. Table 3, column 7 shows results of our analyses of whether there were differences in change in scores for each quality of life measure to week 6 and week 22 as a function of drug treatment (ie, the linear trend $\times$ treatment group term). None was significant. The table also shows baseline scores and changes in mean scores on quality of life measures within treatment groups from baseline to week 22. Ninety-five percent confidence intervals are

TABLE 2. DEMOGRAPHIC AND CLINICAL VARIABLES IN THREE TREATMENT GROUPS AT BASELINE

\begin{tabular}{|c|c|c|c|}
\hline \multirow[b]{2}{*}{ Variable } & \multicolumn{3}{|c|}{ Treatment Group } \\
\hline & $\begin{array}{l}\text { Atenolol } \\
(\mathrm{n}=103)\end{array}$ & $\begin{array}{l}\text { Enalapril } \\
(\mathbf{n}=\mathbf{1 0 1})\end{array}$ & $\begin{array}{l}\text { Isradipine } \\
(\mathrm{n}=105)\end{array}$ \\
\hline \multicolumn{4}{|l|}{ Demographic } \\
\hline Age at entry & $68.1 \pm 0.5$ & $67.7 \pm 0.5$ & $67.9 \pm 0.5^{x}$ \\
\hline Education: median school year completed & 12 & 12 & 12 \\
\hline \multicolumn{4}{|l|}{ Current marital status } \\
\hline Percent married & 58.7 & 61.2 & 50.5 \\
\hline Percent widowed & 30.8 & 30.1 & 31.8 \\
\hline Household income & $\$ 11,700$ & $\$ 12,100$ & $\$ 11,900$ \\
\hline \multicolumn{4}{|l|}{ Clinical } \\
\hline Height (in.) & $64 \pm 0.3$ & $63 \pm 0.3$ & $63 \pm 0.3$ \\
\hline Weight (lb) & $162 \pm 3.1$ & $170 \pm 3.8$ & $166 \pm 3.3$ \\
\hline Sitting systolic blood pressure (mm Hg) & $161.8 \pm 1.5$ & $161.5 \pm 1.5$ & $160.5 \pm 1.4$ \\
\hline Sitting diastolic blood pressure $(\mathrm{mm} \mathrm{Hg})$ & $100.1 \pm 0.5$ & $99.6 \pm 0.5$ & $99.1 \pm 0.4$ \\
\hline Estrogen use concurrent at baseline (\%) & 4.1 & 4.1 & 2.5 \\
\hline
\end{tabular}

*Data on means are reported as means $\pm S E$. 
TABLE 3. QUALITY OF LIFE SCALES AT BASELINE AND CHANGE AFTER ACTIVE THERAPY FOR 22 WEEKS FOR INTENT TO TREAT PATIENTS

\begin{tabular}{|c|c|c|c|c|c|c|c|c|}
\hline \multirow[b]{2}{*}{$\begin{array}{l}\text { Scales and } \\
\text { Areas Assessed }\end{array}$} & \multicolumn{3}{|c|}{ Baseline Mean } & \multicolumn{3}{|c|}{$\begin{array}{l}22 \text { Weeks Change } \\
\text { From Baseline Mean }\end{array}$} & \multirow{2}{*}{$\begin{array}{l}P \text { Value for } \\
\text { Comparisons } \\
\text { Between } \\
\text { Groups From } \\
\text { Baseline to } \\
\text { Weeks } 6 \\
\text { and } 22\end{array}$} & \multirow{2}{*}{$\begin{array}{l}P \text { Value for } \\
\text { Linear Trend } \\
\text { for Combined } \\
\text { Groups From } \\
\text { Baseline to } \\
\text { Weeks } 6 \\
\text { and } 22\end{array}$} \\
\hline & Atenolol & Enalapril & Isradipine & Atenolol & Enalapril & Isradipine & & \\
\hline \multicolumn{9}{|l|}{ Well being } \\
\hline General well being $(+)$ & 104.2 & 104.0 & 105.0 & -1.7 & -0.7 & -0.9 & .969 & .087 \\
\hline \multicolumn{9}{|l|}{ Emotional status } \\
\hline $\begin{array}{l}\text { CESD (depression) (-) } \\
\text { STAI (state }\end{array}$ & 7.5 & 8.5 & 8.4 & 0.1 & -1.9 & -0.5 & .365 & .728 \\
\hline $\begin{array}{l}\text { anxiety) }(-) \\
\text { STAI (trait }\end{array}$ & 29.9 & 31.6 & 29.8 & 0.4 & -0.8 & 0.4 & .626 & .473 \\
\hline $\begin{array}{c}\text { anxiety) }(-) \\
\text { Level of sexual }\end{array}$ & 31.6 & 32.9 & 32.3 & 0.1 & -1.2 & -0.4 & .233 & $.009(\mathrm{Im})$ \\
\hline interest $(+)$ & 2.6 & 2.5 & 2.7 & -0.3 & -0.1 & -0.4 & .329 & $.001(\mathrm{De})$ \\
\hline \multicolumn{9}{|l|}{ Cognitive function } \\
\hline Digit span forward (+) & 7.5 & 7.6 & 7.5 & 0.1 & 0.5 & 0.3 & .543 & $.004(\mathrm{Im})$ \\
\hline Digit span backward (+) & 6.1 & 6.0 & 6.0 & 0.1 & -0.1 & 0.2 & .519 & .570 \\
\hline Digit symbol score $(+)$ & 42.9 & 44.4 & 42.2 & 3.8 & 2.4 & 4.8 & .204 & $.001(\mathrm{Im})$ \\
\hline Trail making A (-) & 51.7 & 47.8 & 51.2 & -4.6 & -7.7 & -7.6 & .593 & $.001(\mathrm{Im})$ \\
\hline Trail making B (-) & 112.6 & 112.3 & 120.3 & -8.9 & -9.9 & -15.7 & .255 & $.001(\mathrm{Im})$ \\
\hline \multicolumn{9}{|l|}{ Physical status } \\
\hline $\begin{array}{l}\text { Physical symptoms } \\
\text { distress (-) }\end{array}$ & 44.6 & 44.1 & 43.2 & 0.4 & 0.2 & 1.6 & .685 & .098 \\
\hline Sleep disturbance $(-)$ & 8.3 & 9.0 & 9.0 & 0.6 & 0.1 & -0.2 & .178 & .691 \\
\hline \multicolumn{9}{|l|}{ Social roles } \\
\hline Social activities $(+)$ & 22.8 & 22.9 & 23.6 & 0.5 & 0.8 & 0.5 & .402 & $.011(\mathrm{Im})$ \\
\hline
\end{tabular}

Baseline means and mean change to 22 weeks. Comparisons between groups based on linear trends from baseline to 6 and 22 weeks. Linear trend for total population. Atenolol $(n=103)$, enalapril $(n=101)$, isradipine $(n=105)$.

For assessment of changes in means, plus sign next to titie of scale denotes improvement with an increasing score, and minus sign denotes improvement with a decreasing score. No mean changes were significant between groups. Significance levels for the CESD and Physical Symptoms Distress measures are based on Iog transformations of the diata.

For linear trend assessment: "In" indicates improvement, ie, less depression, less anxiety, improved performance on cognitive tests. "De" indicates "decline" or "decrease" as shown in Level of Sexual Interest.

For all 13 baseline sets of means, the standard error differed by no more than 0.2 points across the three drug groups, except Trail Making $A$ (0.7) and Trail Making $B$ (0.4). For all 13 sets of means of change, the standard error differed by no more than 0.3 points except for Trail Making A (0.6) and Trail Making $B$ (0.4).

shown in Table 4, reporting on comparisons of each pair of drug treatment groups in degree of change from baseline.

We also carried out separate supplementary repeated measures analysis of variance for the 240 patients who completed three interviews and 22 weeks of treatment. Results of the trend analysis mirrored those deriving from analysis of the intent-to-treat population. In addition, to look specifically at shortterm drug effects we compared the treatment groups at 6 weeks, including all patients who were present at that time $(n=302)$. No differences between treatment groups at that time were found in change on the quality of life scale scores.

Drug Groups Combined Considering mean scores for the three drug groups combined, there were several significant linear trends over the 22 weeks for the total population, as seen in the final column of Table 3. They included decrease (improvement) on the Trait
Anxiety $(P=.009)$ and decline in Level of Sexual Interest $(P=.001)$. Improvements were seen in the Digit Span Forward test $(P=.004)$, Digit Symbol $(P<$ $.001)$, and the Trailmaking $A$ and $B$ tests $(P<.001, P$ $<.001$, respectively). The Social Activities Scale showed an increase in activity $(P<.01)$.

With regard to indicators of physical health, we found no change in scores on the Physical Symptoms Distress Index over the 22 weeks. Examination of two subscales of the General Well Being Adjustment scale, ie, vitality and general health, showed no significant time trends in scores for the patient groups combined, and no between-group differences over the 22 weeks. Results were similar in the analysis of the 240 patients in the "completer" group.

Change in Quality of Life Measures to Week 22: Influence of Age, Titration, and Diuretics as Covariates Through analysis of covariance, we explored whether there was significant between-group change in the quality 
TABLE 4. NINETY-FIVE PERCENT CONFIDENCE INTERVALS FOR COMPARISON BETWEEN DRUG TREATMENT GROUPS IN CHANGE SCORES FROM BASELINE TO WEEK 22

\begin{tabular}{lccc}
\hline Scales and Areas Assessed & $\begin{array}{c}\text { Atenolol } \boldsymbol{v} \\
\text { Enalapril }\end{array}$ & $\begin{array}{c}\text { Atenolol } v \\
\text { Isradipine }\end{array}$ & $\begin{array}{c}\text { Enalapril } v \\
\text { Isradipine }\end{array}$ \\
\hline Well being & & & \\
$\quad$ General well being & $(-6.0,1.7)$ & $(-3.1,4.4)$ & $(-5.5,2.6)$ \\
Emotional status & & $(-2.6,1.7)$ & $(-2.6,3.6)$ \\
CESD (depression) & $(-2.0,3.9)$ & $(-4.5,1.9)$ & $(-2.5,4.1)$ \\
STAI (state anxiety) & $(-1.6,5.8)$ & $(-2.6,1.0)$ & $(-1.6,1.9)$ \\
STAI (trait anxiety) & $(-0.9,2.8)$ & $(-0.3,0.3)$ & $(-0.1,0.8)$ \\
$\quad$ Level of sexual interest & $(-0.5,0.1)$ & $(-0.5,0.4)$ & $(-0.9,2.7)$ \\
Cognitive function & $(-0.1,0.8)$ & $(-0.7,2.9)$ & $(-6.4,4.2)$ \\
$\quad$ Digit span forward & $(-0.7,0.2)$ & $(-0.5,4.1)$ & $(-40.4,18.4)$ \\
Digit span backward & $(-1.9,2.1)$ & $(-5.5,5.3)$ & $(-0.5,3.7)$ \\
Digit symbol score & $(-6.4,2.7)$ & $(-21.8,40.8)$ & $(-1.0,0.9)$ \\
$\quad$ Trail making A & $(-48.8,7.8)$ & $(-0.1,3.6)$ & $(-1.3,0.9)$ \\
$\quad$ Trail making B & $(-2.2,1.9)$ & $(-1.6,0.3)$ & \\
Physical status & $(-0.4,1.5)$ & $(-0.9,0.9)$ & \\
$\quad$ Physical symptoms distress & & &
\end{tabular}

of life measures when age, titration level, or the addition of diuretics was covaried with treatment groups. We found no evidence of an effect of these variables on change in any of the quality of life scale measures.

Distress Over Symptoms: Changes During Therapy While the total scores for the Physical Symptoms Distress Index showed no between-group differences at weeks 6 or 22, we compared the drug groups in distress on the 33 individual perceived symptoms that comprise the Index. (See Appendix A for symptoms list.) Results showing significant comparisons are shown in Table 5. Ninety-five percent confidence intervals appear in Table 6 reporting on comparisons of each pair of drug groups in degree of change from baseline.

Six Weeks From baseline to 6 weeks enalapril patients worsened in their distress over cough as compared with atenolol $(P<.001)$ and isradipine patients $(P<.001)$. The atenolol patients as compared with isradipine patients worsened in their degree of distress concerning tiredness and shortness of breath $(P$

TABLE 5. MEAN CHANGES $(\times 10)$ IN REPORTED DISTRESS OVER SELECTED SYMPTOMS FROM BASELINE TO WEEK 6 AND WEEK 22 BY BETWEEN-GROUP COMPARISONS AND WITHIN-GROUP CHANGES FOR INTENT TO TREAT SAMPLET

\begin{tabular}{|c|c|c|c|c|c|c|c|c|}
\hline \multirow[b]{2}{*}{ Symptomt } & \multicolumn{3}{|c|}{$\begin{array}{c}\text { Week } 6 \\
\text { Change From Baseline }\end{array}$} & \multirow{2}{*}{$\begin{array}{c}\text { Comparison } \\
\text { Between Groups } \\
\text { in Changes } \\
\text { From Baseline } \\
(P \text { Value) }\end{array}$} & \multicolumn{3}{|c|}{$\begin{array}{c}\text { Week 22 } \\
\text { Change From Baseline }\end{array}$} & \multirow{2}{*}{$\begin{array}{c}\text { Comparison } \\
\text { Between Group } \\
\text { in Changes } \\
\text { From Baseline } \\
\text { ( } P \text { Value) }\end{array}$} \\
\hline & $\begin{array}{c}\text { Atenolol } \\
\text { (n = 103) } \\
\text { (A) }\end{array}$ & $\begin{array}{c}\text { Enalapril } \\
\text { ( } \mathrm{n}=101) \\
\text { (B) }\end{array}$ & $\begin{array}{l}\text { Isradipine } \\
\text { (n = 105) } \\
\text { (C) }\end{array}$ & & $\begin{array}{c}\text { Atenolol } \\
(\mathrm{n}=103) \\
(\mathrm{A})\end{array}$ & $\begin{array}{c}\text { Enalapril } \\
\text { (n = 101) } \\
\text { (B) }\end{array}$ & $\begin{array}{c}\text { Isradipine } \\
(\mathrm{n}=105) \\
\text { (C) }\end{array}$ & \\
\hline Cough & -0.9 & $+5.0^{* * *}$ & +0.9 & $\mathrm{~B}>\mathrm{A}, \mathrm{C}^{* * *}$ & +0.3 & $+5.0^{* * *}$ & +0.8 & $\mathrm{~B}>\mathrm{A}, \mathrm{C}^{* * *}$ \\
\hline Dry mouth & +1.1 & +0.1 & -0.1 & NS & +0.9 & $-1.0^{*}$ & -0.4 & $\mathrm{~A}>\mathrm{B}^{* * *}$ \\
\hline Tiredness or fatigue & $+3.3^{* *}$ & -0.2 & -0.2 & $\mathrm{~A}>\mathrm{B}, \mathrm{C}^{* *}$ & +0.5 & -1.7 & +0.1 & NS \\
\hline Shortness of breath & $+1.9^{*}$ & +0.5 & -0.1 & $\mathrm{~A}>\mathrm{C}^{*}$ & 0 & -0.7 & +0.7 & NS \\
\hline $\begin{array}{l}\text { Sensitivity to cold } \\
\text { in extremities }\end{array}$ & $+1.5^{*}$ & -0.7 & 0 & $\mathrm{~A}>\mathrm{B}, \mathrm{C}^{*}$ & +0.7 & -0.3 & +0.3 & NS \\
\hline
\end{tabular}

tThe results for each physical symptom distress measure were based on a 5-point scale (1-5). Plus sign shows worsening for the symptom. Minus sign shows improvement. Within-group comparisons show significance level of degree of change from baseline by asterisks.

$\ddagger$ Week 22 groups contain all patients without segregation by diuretic. With effects of diuretic controlled through ANCOVA, results at 22 weeks showed no differences in levels of significance other than those reported in the table.

${ }^{*} \mathrm{P}<.05$.

$* * \mathrm{P}<.01$.

$* * * \mathrm{P}<.001$ 
TABLE 6. NINETY-FIVE PERCENT CONFIDENCE INTERVALS $(\times 10)$ FOR COMPARISONS BETWEEN TREATMENT GROUPS IN CHANGE SCORES IN DISTRESS OVER SYMPTOMS, FROM BASELINE TO WEEK 6 AND WEEK 22

\begin{tabular}{|c|c|c|c|c|c|c|}
\hline \multirow[b]{2}{*}{ Symptom } & \multicolumn{3}{|c|}{ Week 6} & \multicolumn{3}{|c|}{ Week 22} \\
\hline & $\begin{array}{l}\text { Atenolol } v \\
\text { Enalapril }\end{array}$ & $\begin{array}{l}\text { Atenolol } v \\
\text { Isradipine }\end{array}$ & $\begin{array}{l}\text { Enalapril } v \\
\text { Isradipine } \\
\end{array}$ & $\begin{array}{l}\text { Atenolol } v \\
\text { Enalapril }\end{array}$ & $\begin{array}{l}\text { Atenolol } v \\
\text { Isradipine }\end{array}$ & $\begin{array}{l}\text { Enalapril } v \\
\text { Isradipine }\end{array}$ \\
\hline $\begin{array}{l}\text { Cough } \\
\text { Dry mouth } \\
\text { Tiredness or } \\
\text { fatigue } \\
\text { Shortness of } \\
\text { breath } \\
\text { Sensitivity } \\
\text { to cold in } \\
\text { extremities }\end{array}$ & $\begin{array}{l}(-9.0,-2.7)^{*} \\
(-1.1,2.9) \\
(0.7,6.3)^{*} \\
(-0.5,3.2)\end{array}$ & $\begin{array}{l}(-0.8,4.3) \\
(-3.0,0.8) \\
(-6.5,-0.5)^{*} \\
(-3.7,-0.2)^{*} \\
(-3.5,-0.5)^{*}\end{array}$ & $\begin{array}{l}(-7.0,-1.3)^{*} \\
(-2.4,2.0) \\
(-2.9,2.9) \\
(-2.2,1.0)\end{array}$ & $\begin{array}{l}(-7.9,-1.5)^{*} \\
(-0.3,-4.0)^{*} \\
(-0.8,5.1) \\
(-1.3,2.8)\end{array}$ & $\begin{array}{l}(-2.2,3.2) \\
(-3.5,1.0) \\
(-3.4,2.7) \\
(-1.4,2.8) \\
(-2.4,1.6)\end{array}$ & $\begin{array}{l}(-7.2,-1.4)^{*} \\
(-1.5,2.7) \\
(-1.2,4.8) \\
(-0.6,3.4)\end{array}$ \\
\hline
\end{tabular}

$=.016, P=.019)$. As compared with both enalapril and isradipine patients, atenolol patients also had more distress over cold extremities $(P=.020)$.

Twenty-Two Weeks Review of changes from baseline to 22 weeks showed a reduction in the number of symptoms on which the treatment groups differed. There was a worsening in distress over cough among enalapril patients as compared with those on atenolol or isradipine $(P<.001)$. In addition, there was increased distress over dry mouth in atenolol patients as compared with those taking enalapril $(P<.014)$.

Repeated measures analysis of the linear trend in symptoms distress item scores from baseline to weeks 6 and 22 was carried out (Table 5). Differences between drug groups appeared in cough $(P=.001)$ and tiredness $(P=.048)$ with distress increasing in the enalapril group for cough and atenolol for tiredness. Supplementary analysis of only the 240 patients in the "completer" population produced results that duplicated those in the intent-to-treat analysis in terms of absence of significant differences.

Age, Titration, Diuretics, and Change in Symptoms Distress In comparisons between drug treatment groups, when we considered age, drug titration level, and diuretic usage by means of analysis of covariance, we found no evidence that these three covariates accounted for differences in change in reported symptoms distress for any of the 33 items.

\section{DISCUSSION}

A primary finding in regard to the changes in scores of the quality of life measures was the lack of significant differences between drug treatment groups in measures of general well being, cognitive function, emotional status, and social role performance from baseline to week 6 and to week 22. This was seen in the intent-to-treat analysis and in the analysis of completers.

The rate of withdrawal from a clinical trial because of adverse reactions to the medications is often a ready index of negative impact on quality of life, insofar as it suggests that the effects of the drugs were so negative they could not be tolerated. We found, however, no significant differences between drug groups in the percentage of withdrawals over the 22 weeks of treatment.

Considering the total patient group without drug classification, we found reduction in trait anxiety as well as improvement in cognitive test scores. Without a placebo control group we cannot attribute such improvement to antihypertensive drug treatment. Small decline in anxiety with repeated office visits and the positive effects of practice on cognitive test scores are well-known phenomena in psychological studies.

We did not find relationships between age or dosage level and change in quality of life scale measures. Previous research has shown that the addition of diuretics to monotherapy may reduce differences between the drug groups in changes in quality of life scale scores. ${ }^{34}$ However, the number of patients taking hydrochlorothiazide in each treatment group was relatively small and we did not find such effects of diuretics in this study.

In terms of change in reported distress over symptoms, there were no significant differences between the drug groups in scores on the total Physical Symptoms Distress Index at weeks 6 or 22.

Among the 33 individual symptoms distress items examined, however, we identified a small subset in which (a) patients from the three treatment groups differed in response, and (b) the nature of response differed by the length of treatment. Some symptoms distress reported at 6 weeks with atenolol was improved at 22 weeks. This improvement cannot be ex- 
plained by selective withdrawal because of the side effects. Notably, at 22 weeks the three groups differed in change on only two symptoms-worsening of cough among enalapril patients and dry mouth among atenolol patients. In the isradipine treatment group no worsening in distress over symptoms appeared from baseline to week 6 or week 22 on any of the physical symptoms distress items for which differences between drug groups were detected. The data on linear trends in distress over dry mouth in atenolol patients and cough in enalapril patients are consistent with known effects of these agents.

With negative findings there is the question of adequate statistical power to detect meaningful differences. The power analysis showed failure to detect a medium effect ( $95 \%$ power) to be highly unlikely. Further, as indicated in the footnote to Table 3 , the standard errors of the mean changes are relatively small for each of the quality of life scales.

This clinical trial examined a group of elderly hypertensive women who fit a specified demographic and clinical profile, and the results do not necessarily generalize to other populations. Our findings regarding atenolol, enalapril, and isradipine are specific to those drugs and the assigned dosages.

The measures selected for this study and for earlier clinical trials in which the first author participated were chosen in line with a conceptualization of the dimensions of quality of life and of the construct. ${ }^{5,13,29}$ In this research several primary measures of areas of quality of life are the same as were employed in those previous clinical trials, having been selected on the basis of wide usage, reliability, validity, and relevance ${ }^{35-38}$ For assessment of additional dimensions of cognitive functioning and of mood state, ie, anxiety and depression, we also added established instruments that are widely employed in aging studies and in studies of the effects of hypertension on behavior. ${ }^{39-42}$ Additional measures for this study necessarily had to be either adapted from other instruments or developed to fit the special requirements of research on this elderly female population and this particular set of antihypertensive drugs. ${ }^{43-45}$

Considering recent large randomized clinical trials concerned with quality of life that have included female patients, and one or more of the antihypertensive medications examined here, ${ }^{11-15,17,20}$ it is notable that reported findings have been generally similar to ours concerning the relatively minimal impact of the medications on quality of life measures. Although caution must be exercised in drawing conclusions about comparisons between clinical trials, such findings appear to emerge despite diversity in methods, study populations, research design, quality of life measures, and assessment of perceived symptoms and side effects. Given that in this study the three treatment drugs appear similar in their efficacy and in their effects on the series of quality of life measures, our findings may suggest that the clinician increasingly has a broader range of choices and can more closely tailor the treatment to specific characteristics of the elderly female patient and to the desired additional secondary effects of the medications.

\section{ACKNOWLEDGMENTS}

We thank the following clinical investigators for their contributions to this research: M. DeWayne Andrews, M.D., University of Oklahoma College of Medicine, Oklahoma City, Oklahoma; David M. Bartels, Pharm.D., University of Illinois College of Medicine, Rockford, Illinois; Joan Benz, M.D., Cedar Rapids, Iowa; Gerald S. Berenson, M.D., LSU Medical Center, New Orleans, Louisiana; Nemat Borhani, M.D., University of California, Davis, California; William Brubaker, M.D., Boulder, Colorado; Mary Chandler, Pharm.D., College of Pharmacy, University of Kentucky Medical Center, Lexington, Kentucky; E.E. Eddleman, M.D., SACCI, Birmingham, Alabama; Larry I. Gilderman D.O., Pembroke Pines, Florida; David Ginsberg, D.O., Harleysville, Pennsylvania; Insung Kim, M.D., University of Texas Health Science Center, San Antonio, Texas; John B. Kostis, M.D., University of Medicine and Dentistry of New Jersey, Robert Wood Johnson Medical School, New Brunswick, New Jersey; Charles Lucas, M.D., Preventive and Nutritional Medicine, Birmingham, Michigan; Charles Marsh, Pharm.D., University of Arkansas for Medical Sciences, Fort Smith, Arkansas; Joel Morganroth, M.D., Philadelphia, Pennsylvania; Thomas Petrin, M.D., Midwest Research Institute, Indianapolis, Indiana; Gary E. Ruoff, M.D., Westside Family Medical Center, Kalamazoo, Michigan; Harold W. Schnaper, M.D., University of Alabama, Birmingham, Alabama; Harold M. Silberman, M.D., Coral Gables, Florida; McFate Smith, M.D., San Francisco, California; Raymond Townsend, M.D., University of Texas Medical Branch, Galveston, Texas; Phillip Zager, M.D., University of New Mexico School of Medicine, Albuquerque, New Mexico.

\section{APPENDIX A: MEASURES USED TO ASSESS AREAS OF QUALITY OF LIFE}

\section{WELL-BEING}

Sense of Well-Being ${ }^{35-37}$ The General Well-Being Adjustment Scale (Rand) consists of 22 questions on the following subscales: anxiety, depression, general health, positive well-being, self-control, and vitality. Patients rate each question on a 6-point scale. The total index, consisting of the sum of the subscales, ranges from 22 to 132, with a high score indicating greater well-being. The internal consistency reliability (Cronbach's $\alpha$ ) is 0.94 for the full scale.

\section{EMOTIONAL STATUS}

CESD-Depression Scale ${ }^{39,40}$ The CESD Scale (Center for Epidemiologic Studies-Depression) is designed to measure depressive symptomatology in the general population. The scale centers on 20 dysphoric and somatic complaints that often accompany depressive mood but which may not constitute criteria for the clinical syndrome of depression. Patients rate each symptom on a 4-point scale indicating the num

Scor

Lev

whic

"Du

sexu

from

Dig
the
ory
sam
tition
high
Dig
Wec
ject
and
perf
Tra
Mak
mot
quir
The
circl
ters.
seco
ages

Phy

rate

of d

beca

on $\mathrm{i}$

Lun

up $\mathrm{F}$

on $t$

vom

dizz

skin

face

slow

cold

or d

ston

nati

ness 
number of days the symptom was experienced during the previous week. Responses range from "less than 1 day" to "5 to 7 days." Total scores for the scale range from 0 (low) to 60 (high).

State Anxiety Scale; Trait Anxiety Scale ${ }^{41}$ The STAI (Spielberger) consists of two sets of 20 questions to assess state anxiety and trait anxiety. In responding to the State Anxiety scale, the patient rates each self-descriptive item in regard to how she is feeling "right now." For the Trait Anxiety scale the patient rates a series of descriptors in regard to how she feels generally. Ratings are made on a 4-point scale, ranging from "Not at all" to "Very much so." Scores for each scale range from 20 (low) to 80 (high).

Level of Sexual Interest This is a single item scale to which all patients responded. It consists of the question: "During the past month, how would you rate your current level of sexual interest? Consider the frequency of your sexual urges, fantasies, and thoughts." The scale ranges from no interest $(0)$ to very high interest (7).

\section{COGNITIVE FUNCTION}

Digit Span Test ${ }^{42}$ The Digit Span test is a subtest from the Wechsler Adult Intelligence Scale that measures memory retentiveness. It involves repetition of digits in the same order as they are spoken by the examiner and repetition of digits in the reverse order. Higher scores indicate higher retentiveness.

Digit Symbol $^{42}$ The Digit Symbol test is a subtest of the Wechsler Adult Intelligence Scale and requires the subject to associate symbols with other symbols, testing speed and accuracy in the task. Higher score indicates higher performance.

Trail Making A; Trail Making $\mathbf{B}^{38}$ The Reitan Trail Making Test is a two-part instrument for assessing visualmotor speed and integration. The Trail Making A test requires the patient to connect circles by consecutive number. The Trail Making B test requires that the subject connect circles by alternate consecutive numbers and alphabet letters. The score for each test is based on the total number of seconds required to accomplish the task of connecting images by drawing lines.

\section{PHYSICAL STATUS}

Physical Symptoms Distress Index-EW Patients rate each of 33 reported symptoms in regard to the degree of distress they experienced during the previous month because of the symptoms. The symptoms are based in part on items used in questionnaires in the National Heart, Lung, and Blood Institute Hypertension Detection Followup Program, in part on side effects reported in the literature on the three treatment drugs. ${ }^{43}$ The items include: tiredness or fatigue, feeling weak, headaches, feeling nauseous, vomiting, diarrhea, constipation, feeling flushed, feeling dizzy or lightheaded when standing up quickly, fainting, skin rash, stuffy nose, feeling swelling in throat, tongue, or face, swelling of ankles, cough, trouble falling asleep, nightmares, feeling anxious, heart beating unusually slowly, heart beating unusually fast, feeling sensitive to cold in hands or feet, feeling depressed and blue, wheezing or difficulty breathing, blurry vision, pain in joints, upset stomach or heartburn, excessive dry mouth, frequent urination, heart pounding or fluttering, muscle cramps, shortness of breath, pains in heart or chest, loss of taste or change in taste sensations. The ratings are on a 5-point scale, ranging from "Not at all" to "Extremely," with a range in scores from 33 (low) to 165 (high), $\alpha=0.82$. The format is based on the Brief Symptom Inventory. ${ }^{44}$ The Index is a modification of the Physical Symptoms Distress Index earlier employed elsewhere. ${ }^{5}$

Sleep Disturbance Index ${ }^{45}$ The Sleep Disturbance scale, which was adapted from previous work, consists of four questions that measure number of days in which there were problems in falling asleep, staying asleep, early awakening, and awakening tired. Scores range from 4 (no sleep disturbance) to 20 (high sleep disturbance). Cronbach's $\alpha=$ 0.79 .

Vitality, General Health These measures are subscales of the General Well-Being Adjustment Scale cited above. ${ }^{36}$

\section{SOCIAL ROLES}

Social Participation Activities Scale This is a 9-question scale which assesses frequency of participation during the past month in a series of common social and recreational activities, including such items as visiting with friends or relatives, community activities, hobbies, and telephone conversations with friends or relatives. Ratings on a 6-point scale range from "Not at all" (0) to "Daily" (4), and scores for the total scale range from 0 (low) to 45 (high). Cronbach's $\alpha=0.66$.

\section{REFERENCES}

1. Working Group on Hypertension in the Elderly: Statement on hypertension in the elderly. JAMA 1986;256: $70-74$.

2. Subcommittee on Definition and Prevalence of the 1984 Joint National Committee: Hypertension prevalence and the status of awareness, treatment, and control in the United States. Hypertension 1985;7:457468.

3. Weinberger MH: Hypertension in the elderly: impact, pathophysiology, and treatment, in Punzi HA, Flamenbaum W (eds.): Hypertension. Mount Kisco, NY, Futura Publishing Co., 1989, pp 269-282.

4. National Heart, Lung, and Blood Institute: 1988 Joint National Committee. The 1988 report of the Joint National Committee on Detection, Evaluation, and Treatment of High Blood Pressure. Ann Intern Med 1988; 148:1023-1038.

5. Croog SH, Levine S, Testa MA, et al: The effects of antihypertensive therapy on quality of life. N Engl J Med 1986;314:1657-1664.

6. Bulpitt CJ: Quality of life in hypertensive patients, in Amery A, Fagard R, Lijnen P, Staessen J (eds.): Hypertensive cardiovascular disease: pathophysiology and treatment. The Hague, Martinus Nijhoff, 1982, pp 929-948.

7. Williams GH: Converting-enzyme inhibitors in the treatment of hypertension. N Engl J Med 1988;319: 1517-1525.

8. Herrick AL, Waller PC, Berkin KE, et al: Comparison of enalapril and atenolol in mild to moderate hypertension. Am J Med 1989;86:421-426.

9. Fitton A, Benfield P: Isradipine. A review of its pharmacodynamic and pharmacokinetic properties. Drugs 1990;40:31-74. 
10. Eisner GM, Johnson BJ, McMahon FG, et al: A multicenter comparison of the safety and efficacy of isradipine and enalapril in the treatment of hypertension. Am J Hypertens 1991;4:154S-157S.

11. Fletcher AE, Bulpitt CJ, Chase DM, et al: Quality of life with three antihypertensive treatments: cilazapril, atenolol, nifedipine. Hypertension 1992;19:499-507.

12. Palmer AJ, Fletcher AE, Rudge PJ, et al: Quality of life in hypertensives treated with atenolol or captopril: a double-blind crossover trial. J Hypertens 1992;10: 1409-1416.

13. Croog SH, Kong BW, Levine S, et al: Hypertensive black men and women: quality of life and effects of antihypertensive medications. Arch Intern Med 1990; 150:1733-1741.

14. The Treatment of Mild Hypertension Research Group: The treatment of mild hypertension study. Arch Intern Med 1991:151:1413-1423.

15. Wassertheil-Smoller S, Blaufox MD, Oberman A, et al and the TAIM Research Group: Effect of antihypertensives on sexual function and quality of life: the TAIM study. Ann Intern Med 1991;114:613-620.

16. Testa MA, Anderson RB, Nackley BA, Hollenberg NK, and the Quality of Life Hypertension Study Group: Quality of life and antihypertensive therapy in men. A comparison of captopril with enalapril. N Engl J Med 1993;328:907-913.

17. deLame PA, Droussin AM, Thomson $M$, et al: The effects of enalapril on hypertension and quality of life. Acta Cardiol 1989;44:289-302.

18. Steiner SS, Friedhoff AJ, Wilson BL, et al: Antihypertensive therapy and quality of life: a comparison of atenolol, captopril, enalapril, and propranolol. J Hum Hypertens 1990;4:217-225.

19. Goldstein G, Matterson BJ, Cushman WC, et al, for the Department of Veterans Affairs Cooperative Study: Treatment of hypertension in the elderly. II. Cognitive and behavioral function. Hypertension 1990;15:361-369.

20. Applegate WB, Phillips $\mathrm{HL}$, Schnaper $\mathrm{H}$, et al: A randomized controlled trial of the effects of three antihypertensive agents on blood pressure control and quality of life in older women. Arch Intern Med 1991;151: 1817-1823.

21. Elias MF, Robbins MA, Schultz NR, Jr, et al: Clinical significance of cognitive performance by hypertensive patients. Hypertension 1987;9:192-197.

22. Muldoon MF, Shapiro AP, Manuck SP, Waldstein SR: Behavioral sequelae of antihypertensive therapy: a review, in Shapiro AP, Baum A (eds.): Behavioral Aspects of Cardiovascular Disease. Hillsdale, NJ, Lawrence Erlbaum Assoc., 1991, p 287.

23. Applegate WB: Hypertension in elderly patients. Ann Intern Med 1989;119:901-905.

24. Elias MF, Robbins MA: Cardiovascular disease, hypertension, and cognitive function, in Shapiro AP, Baume A (eds.): Behavioral Aspects of Cardiovascular Disease. Hillsdale, NJ, Lawrence Erlbaum Assoc., 1991, pp 249-286.

25. Perry HM, Hall WD, Benz JR, et al: Efficacy and safety of atenolol, enalapril and isradipine in elderly hypertensive women. Am J Med (in press).

26. Romano PE: Optotype distortion on the "Rosenbaum Pocket Vision Screener." Ann Ophthalmol 1989;21: 362-363.

27. Jastak JF, Jastak S: Wide range achievement test. Wilmington, DE, Jastak Associates, 1978.

28. Folstein MF, Folstein SE, McHugh PH. Mini-mental state: a practical method for grading the cognitive state of patients for the clinician. J Psychiatric Res 1975;12:189-198.

29. Levine S, Croog SH: What constitutes quality of life? A conceptualization of the dimensions of life quality in healthy populations and patients with cardiovascular disease, in Wenger NK, Mattson ME, Furberg CD, Elinson J (eds.): Assessment of Quality of Life in Clinical Trials of Cardiovascular Therapies. New York, LeJacq Communications, 1984, pp 46-58.

30. Croog SH: Quality of life and the hypertensive patient: clinical aspects, in Punzi HA, Flamenbaum W (eds.): Hypertension. Mount Kisco, NY, Futura Publishing, 1989, pp 221-246.

31. Winer BJ: Statistical Principles in Experimental Design, 2nd ed. New York, McGraw-Hill, 1971.

32. Sachs L: Applied Statistics: A Handbook of Techniques, 2nd ed. New York, Springer-Verlag, 1984.

33. Cohen J: Statistical Power Analysis for the Behavioral Sciences, 2nd ed. Hillsdale, NJ, Lawrence Erlbaum Associates, 1988.

34. Williams $\mathrm{GH}$, Croog $\mathrm{SH}$, Levine $\mathrm{S}$, et al: Impact of antihypertensive therapy on quality of life: effect of hydrochlorothiazide. J Hypertens 1987;5(suppl 1):S29 S35.

35. Ware JE Jr, Brook RH, Davies-Avery A, et al: Conceptualization and Measurement of Health for Adults in the Health Insurance Study. Vol. I. Model of Health and Methodology. Santa Monica, CA, Rand Corporation, 1980.

36. Ware JE Jr, Johnston SA, Davies-Avery A, Brook RH; Conceptualization and Measurement of Health for Adults in the Health Insurance Study. Vol. III. Mental Health. Santa Monica, CA, Rand Corporation, 1979.

37. Brook RH, Ware JE Jr, Davies-Avery A, et al: Conceptualization and Measurement of Health for Adults in the Health Insurance Study. Vol. VIII. Overview. Santa Monica, CA, Rand Corporation, 1979.

38. Reitan RM: Trail Making Manual for Administration, Scoring, and Interpretation. Indianapolis, Department of Neurology, Section of Neuropsychology, Indiana University Medical Center, 1958.

39. Radloff LS: The CES-D scale: a self-report depression scale for research in the general population. Appl Psych Measure 1977;1:385-401.

40. Hertzog C, Van Alstine Jr, Usala PD, et al: Measurement properties of the Center for Epidemiological Studies Depression Scale (CES-D) in older populations. J Consult Clin Psych 1990;2:64-72.

41. Spielberger CD, Gorsuch RL, Lushene RE: STAI Manual for the State/Trait Anxiety Inventory. Palo Alto, CA, Consulting Psychologists Press, 1970. 
42. Wechsler D: Manual for the Wechsler Adult Intelligence Scale. New York, Psychological Corporation, 1955.

43. Hypertension Detection and Follow-up Program Cooperation Group: The effect of treatment on mortality in "mild" hypertension: results of the Hypertension Detection and Follow-up Program. N Engl J Med 1982; 307:976-80.

44. Derogatis LR, Spencer PM: The Brief Symptom Inven- tory (BSI), Administration, Scoring and Procedures Manual I. Baltimore, Johns Hopkins University School of Medicine, 1982. (Privately printed.)

45. Rose RM, Jenkins CD, Hurst MW: Air traffic controller health change study. Report to Federal Aviation Administration, August 1978. Boston, Boston University School of Medicine. Document FAA-AM 78-39 (Available from the National Technical Information Service, Springfield, VA 22161.) 